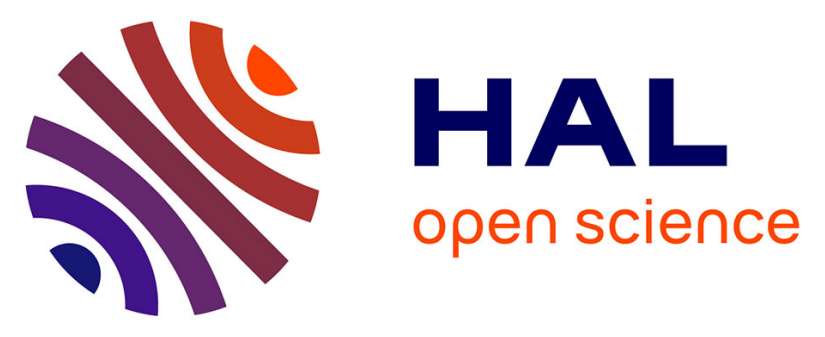

\title{
First steps towards the thermomechanical characterization of chalcogenide glass using quantitative infrared thermography
}

Eric Robin, Jean-Benoit Le Cam, Xavier Balandraud, Evelyne Toussaint, Laurent Brilland

\section{To cite this version:}

Eric Robin, Jean-Benoit Le Cam, Xavier Balandraud, Evelyne Toussaint, Laurent Brilland. First steps towards the thermomechanical characterization of chalcogenide glass using quantitative infrared thermography. Journal of Non-Crystalline Solids, 2014, 391, pp.101-105. 10.1016/j.jnoncrysol.2014.03.015 . hal-01063259

\section{HAL Id: hal-01063259 \\ https://hal.science/hal-01063259}

Submitted on 11 May 2020

HAL is a multi-disciplinary open access archive for the deposit and dissemination of scientific research documents, whether they are published or not. The documents may come from teaching and research institutions in France or abroad, or from public or private research centers.
L'archive ouverte pluridisciplinaire HAL, est destinée au dépôt et à la diffusion de documents scientifiques de niveau recherche, publiés ou non, émanant des établissements d'enseignement et de recherche français ou étrangers, des laboratoires publics ou privés. 


\title{
First steps towards the thermomechanical characterization of chalcogenide glass using quantitative infrared thermography
}

\author{
Eric Robin ${ }^{\mathrm{a}}$, Jean-Benoît Le Cam ${ }^{\mathrm{a}, *}$, Xavier Balandraud ${ }^{\mathrm{b}, \mathrm{c}}$, Evelyne Toussaint ${ }^{\mathrm{c}, \mathrm{d}}$, Laurent Brilland ${ }^{\mathrm{e}}$ \\ a Université de Rennes 1, Institut de Physique de Rennes UMR 6251-CNRS/Université de Rennes 1, Campus de Beaulieu, Bât. 10B, 35042 Rennes Cedex, France \\ ${ }^{b}$ Clermont Université, Institut Français de Mécanique Avancée, Institut Pascal, BP 10448, 63000 Clermont-Ferrand, France \\ c CNRS, UMR 6602, Institut Pascal, 63171 Aubière, France \\ d Clermont Université, Université Blaise Pascal, Institut Pascal, BP 10448, 63000 Clermont-Ferrand, France \\ e PERFOS, RED Platform of Photonics Bretagne, F-22300 Lannion, France
}

This paper focuses on the thermoelastic behavior of chalcogenide glasses. For this purpose, an original experiment was developed to measure the thermal field at the surface of an AsSe glass specimen submitted to cyclic mechanical loading. The specimen geometry was chosen in such a way that a high stress gradient was induced by the loading conditions. The temperature field was measured by means of infrared thermography. The framework of thermal stress analysis (TSA) was then used to successfully map the stress field at the surface of the specimen by processing the thermal fields. The main result is that classical thermoelastic response is observed in chalcogenide glass without disturbances such as photo-irradiation. This work is a first step towards the characterization of the thermomechanical sensitivity of chalcogenide glasses.

\section{Introduction}

Chalcogenide glasses have been intensively studied for a decade, due to their particular optical properties, especially their transparency in the infrared domain. This exceptional optical characteristic enables them to be a good choice for infrared component technology, even though their mechanical properties are inferior to those of more classical glasses. Thus, most of the studies reported in the literature focus on their physical and chemical characterization, and more particularly on their interaction with light [1-4], as well as on the relation between their physical properties and chemical formulation [5]. Some studies were dedicated to the mechanical properties of chalcogenide glasses [6-16]. Despite this, the physical mechanisms involved in their optical and mechanical responses are not clearly understood, and other ways of investigation have to be considered in order to provide additional information such as calorific data, energy balance... Among them, infrared (IR) thermography is an experimental technique which provides the full temperature field at the surface of an object. In the context of the thermomechanics of materials, IR cameras are used to capture the temperature changes of specimens subjected to mechanical loadings. Phenomena such as thermoelasticity, fatigue, plasticity, viscosity or phase change lead to temperature changes which can be tracked during mechanical tests. These phenomena are accompanied by heat, produced or absorbed

\footnotetext{
* Corresponding author. Fax: +33223236111.

E-mail address: jean-benoit.lecam@univ-rennes1.fr (J.-B. Le Cam).
}

by the material. For instance, thermoelastic coupling leads to heat production or absorption as a function of the stress variation. This coupling is the fundament of the thermoelastic stress analysis (TSA) technique which, under some test conditions, provides a stress map of the surface of the specimen $[17,18]$. This technique has spread in the experimental mechanics community and has found numerous applications, in particular to metallic materials. The present study applies this type of approach to the mechanics of chalcogenide glasses. For this purpose, an original specimen geometry was used to reveal their thermoelastic sensitivity during compression cyclic tests. Section 2 presents the experimental setup in terms of material, specimen geometry, mechanical loadings and thermal measurements. Section 3 gives the results of thermal measurements at the specimen surface. Lastly, Section 4 presents the stress field obtained from the temperature measurements using the framework of TSA.

\section{Experimental setup}

\subsection{Material and specimen geometry}

The glass considered in the present study is a chalcogenide glass of the AsSe system $\left(\mathrm{As}_{38} \mathrm{Se}_{62}\right)$. Its main properties are presented in Table $1 . T_{g}$ is the glassy temperature, $T_{x}$ is the temperature at the beginning of crystallization, $\rho$ is the density, $\alpha$ is the thermal expansion coefficient, $H_{v}$ is the hardness in Vickers, $G$ is the Coulomb (or shear) modulus, $E$ is the Young modulus and $v$ is Poisson's ratio. The coefficient $A=\alpha T_{0} / \rho C$ will be used for the thermoelastic analysis, where $\rho$ is 
Table 1

Physical and chemical properties of As38Se62.

\begin{tabular}{lc}
\hline Property & Value \\
\hline$T_{g}\left({ }^{\circ} \mathrm{C}\right)$ & 165 \\
$T_{X}\left({ }^{\circ} \mathrm{C}\right)$ & 250 \\
$\Delta T=T_{g}-T_{X}\left({ }^{\circ} \mathrm{C}\right)$ & 85 \\
$\rho\left(\mathrm{kg} / \mathrm{m}^{3}\right)$ & 4530 \\
$\alpha\left(10^{-6} \mathrm{~K}^{-1}\right)$ & 25.4 \\
$C-p\left(\mathrm{~J} \mathrm{~kg}{ }^{-1} \mathrm{~K}^{-1}\right)$ & 360 \\
$H v\left(\mathrm{~kg} / \mathrm{mm}^{2}\right)$ & 133.6 \\
$G(\mathrm{GPa})$ & 6.91 \\
$E(\mathrm{GPa})$ & 17.7 \\
$v(-)$ & 0.279 \\
\hline
\end{tabular}

the density, $\alpha$ the thermal expansion coefficient and $T_{0}$ the mean temperature of the test in Kelvin. For the present material, it is equal to $4.64 \mathrm{mK} / \mathrm{MPa}$ at ambient temperature. The specimen geometry was a $16 \mathrm{~mm}$ diameter disc with a hole whose diameter was equal to $3 \mathrm{~mm}$. The disc thickness was $17.6 \mathrm{~mm}$.

\subsection{Mechanical tests}

The specimen was tested under compressive cyclic loading at ambient temperature using a $15 \mathrm{kN}$ MTS testing machine. An overview of the experimental setup is given in Fig. 1. Table 2 summarizes the cyclic loading conditions applied. $F_{\max }$ and $F_{\min }$ are the maximum and minimum values of the force applied, respectively. The load ratio $R_{F}$, defined as the ratio between the maximum and the minimum values of the force, was equal to 0.1 for all the tests in order to maintain the contact between the disk and the plates. The force range, i.e. twice the force amplitude, is denoted $\Delta F$ in the following. Two loading frequencies $f$ were applied: 1 and $3 \mathrm{~Hz}$. The shape of the effort signal was sinusoidal. Thanks to the low thermal diffusivity of the material compared to metallic and polymer materials, a low frequency (typically of the order of a few Hertz) was assumed to be sufficient to achieve adiabatic conditions within the specimen. This is more precisely addressed in the following.

\subsection{Temperature measurement}

Temperature measurement was performed at ambient temperature using a Cedip Jade III-MWIR infrared camera, which features a matrix of
Table 2

Mechanical tests.

\begin{tabular}{|c|c|c|c|c|}
\hline \multirow[t]{2}{*}{ Specimen number } & $F_{\max }$ & $F_{\min }$ & $f$ & $\Delta F$ \\
\hline & $(\mathrm{N})$ & $(\mathrm{N})$ & $(\mathrm{Hz})$ & $(\mathrm{N})$ \\
\hline 1 & -80 & -8 & 1 & \pm 36 \\
\hline 2 & -80 & -8 & 3 & \pm 36 \\
\hline 3 & -160 & -16 & 1 & \pm 72 \\
\hline 4 & -160 & -16 & 3 & \pm 72 \\
\hline 5 & -240 & -24 & 1 & \pm 108 \\
\hline 6 & -240 & -24 & 3 & \pm 108 \\
\hline
\end{tabular}

$320 \times 240$ pixels with detectors in a wavelength range of 3.5-5 $\mu \mathrm{m}$. The integration time was set to $1500 \mu$ s and the acquisition frequency was equal to $147 \mathrm{~Hz}$. Thermal resolution was equal to $20 \mathrm{mK}$. The size of a pixel, i.e. the individual IR detector size projected on the specimen, was equal to $0.16 \mathrm{~mm}$. During the thermal measurements, a home-made casing surrounded the IR camera in order to avoid any disturbance such as photo-irradiation. To ensure that the internal temperature of the camera was stabilized during the measurements, the camera was set up and switched on $4 \mathrm{~h}$ before the experiment. The stabilization of the temperature inside the camera was necessary to avoid any drift of the measurements during the test. Temperature changes were measured by subtracting the initial temperature, captured in practice just before the beginning of the test, from the current one. In the present study, the initial temperature is the reference temperature. It can be noted that measurement noise was reduced using a spatial filter. In practice, we have applied a mean filter whose kernel dimensions were $5 \times 5$ pixels. The temperature change range $\Delta \theta$, i.e. twice the temperature change amplitude, was extracted at each pixel using a Fourier transform, from several cycles (here during $10 \mathrm{~s}$ ) once the temperature evolution was stabilized.

\subsection{Remarks about test preparation}

It should be pointed out that the brittle nature of glass material makes harder the mechanical tests. Indeed, the first difficulty encountered was the application of a load without breaking the specimen. For this reason, a thin piece of polymer was placed between the grips and

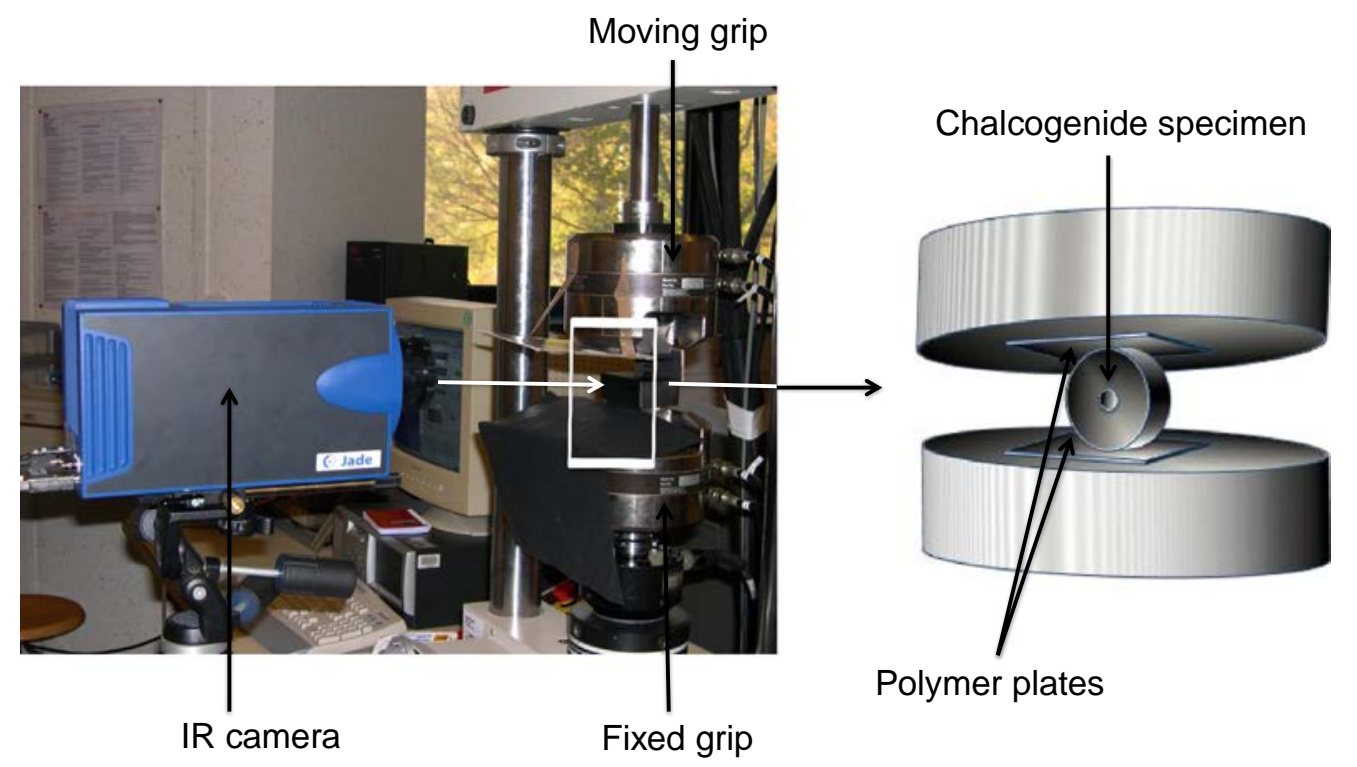

Fig. 1. Overview of the experimental setup. 


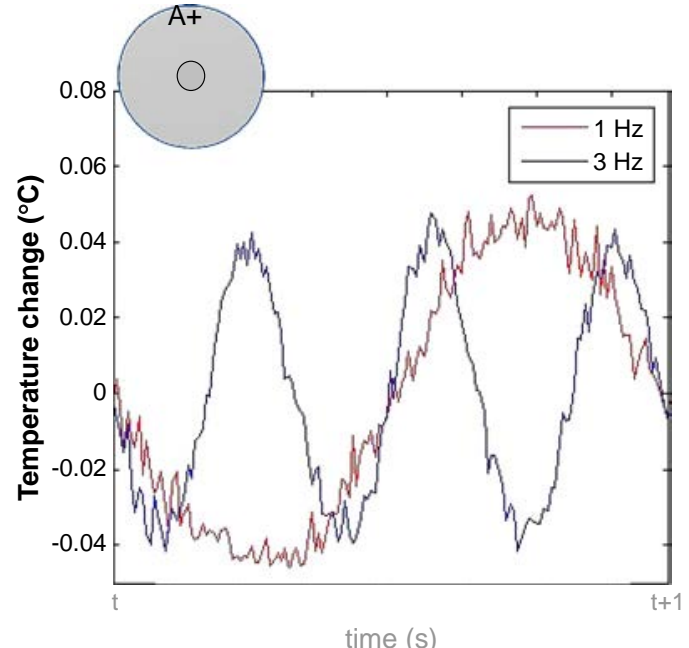

Fig. 2. Temperature change at point A during the tests performed at $1 \mathrm{~Hz}$ and $3 \mathrm{~Hz}(F=$ $-132 \pm 108 \mathrm{~N})$.

the specimen to prevent cracks from being initiated and propagating from the contact zones. As the IR transparency wavelengths in such a chalcogenide material can coincide with the range of those of the IR detectors of the camera (3.5-5 $\mu \mathrm{m})$, a treatment was applied to the specimen surface. This treatment did not modify the mechanical response of the material, but it ensured that surface emissivity was equal to 0.95 . The details about the surface treatment and protection against radiations are not here provided because of industrial confidentiality requirements. Thermal measurements were performed at constant ambient temperature.

\section{Results}

\subsection{Thermal analysis}

The full thermal field was measured at the specimen surface during the cyclic tests. This type of measurement is classically performed to characterize thermal activity and more especially the thermal activity gradient at the specimen surface. This was therefore the first objective of the study. Fig. 2 shows temperature change over time at point A, where the thermal activity was maximum during tests 5 and 6, i.e. for $132 \pm 108 \mathrm{~N}$ at 1 and $3 \mathrm{~Hz}$. Point A corresponds to a pixel located $1 \mathrm{~mm}$ far from the contact zone. The temperature at every pixel of this map is issued from the spatial filtering previously performed. First, it can be observed that the temperature changes oscillate at the same frequency as the load for both cases. This proves that the thermal response of the chalcogenide glass considered in the present study is governed by the thermoelastic coupling. These first results are in good agreement with the previous ones we recently obtained with sodalime glass [19]. For both frequencies, the temperature change ranges are quite the same, meaning that adiabatic conditions are reached in both cases. This is due to the low thermal diffusivity of the material.

Fig. 3 presents the map of temperature change ranges $\Delta \theta$ at the specimen surface obtained for tests 2 and 6 . It is the map of the amplitude of the periodic oscillation of the temperature over the cycles. In practice, a Fourier analysis was done at each pixel on the specimen surface in order to extract the local amplitude at the loading frequency. The map obtained enabled us to clearly distinguish the heterogeneity of the thermal activity at the specimen surface. As expected, the thermal field was nearly symmetrical. The slight asymmetry can be explained by the difference in the boundary conditions. The highest thermal activity was found in zones on both sides of the hole in the direction perpendicular to the applied load, and in zones close to the contact areas between the grips and the specimen. The maximum temperature range was equal to $22 \mathrm{mK}$ (for test 2). It should be noted that thermal resolution was improved by measuring the temperature change range over several cycles. This enabled us to distinguish zones whose temperature differed by a few milli-Kelvin. For all digital cameras, If the spatial resolution of the sensor used (in our case $0.16 \mathrm{~mm} / \mathrm{pixel}$ ) is higher than the spatial dimension of the phenomena observed, the information acquired at the pixel is smoothed (pixelization effect). Consequently at point A (Hertz point) the temperature activities measured due to the stress singularity are averaged. Results obtained for the highest cyclic load applied (test 6) are presented on the right-hand side. The applied load range was equal to $108 \times 2 \mathrm{~N}$, and the corresponding maximum temperature change range attained $70 \mathrm{mK}$. As expected, the thermal activity was localized in the same zones as for lower load ranges, but the level of temperature change range was higher. These first results highlight the fact that infinitesimal temperature changes can be detected and quantified using infrared thermography during the deformation of chalcogenide glass, and that consequently thermomechanical analyses such as those recently carried out for sodalime glass [19] can be performed. Fig. 4 presents the temperature change range $\Delta \theta$ at point $\mathrm{A}$ versus the force range $\Delta F$ for tests performed at $3 \mathrm{~Hz}$. The curve obtained is linear, which allows us to apply a thermoelastic stress analysis in the next section.

\subsection{Thermoelastic stress analysis}

The TSA approach enables us to link the temperature change range with the stress range. More precisely, for an isotropic material, the scalar

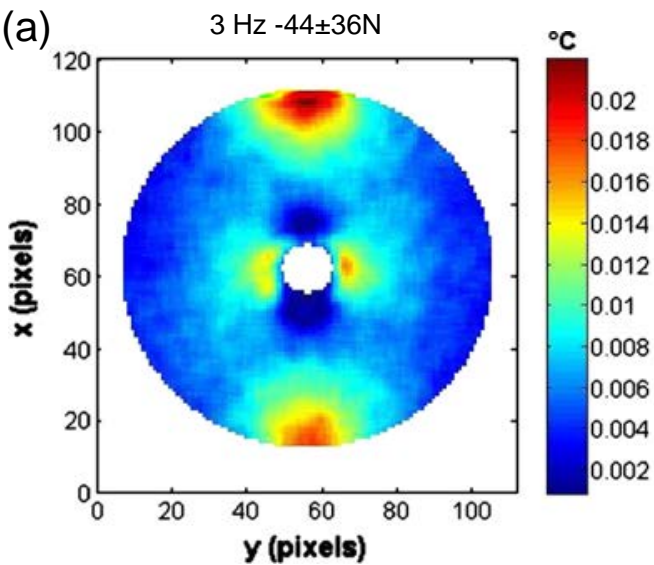

(b)

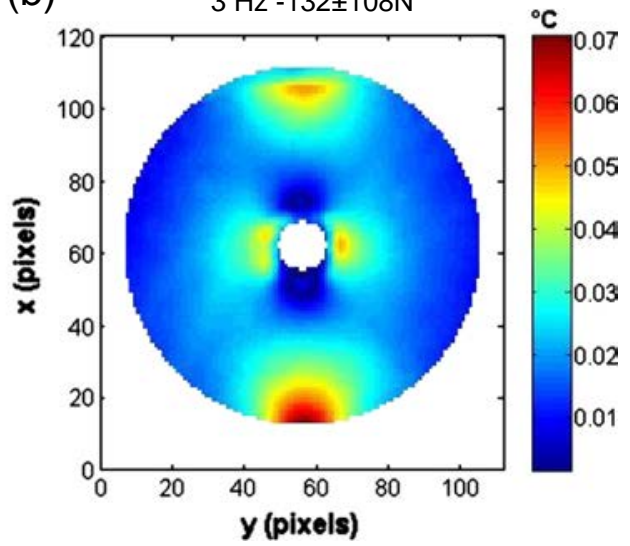

Fig. 3. Map of thermal activity at the specimen surface in terms of temperature change range at $3 \mathrm{~Hz}$. (a) Test $2: F=-44 \pm 36 \mathrm{~N}$. (b) Test $6: F=-132 \pm 108 \mathrm{~N}$. 


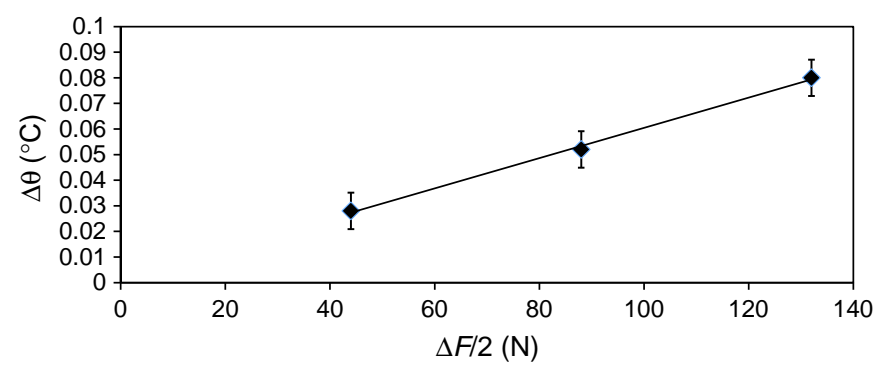

Fig. 4. Temperature change range $\Delta \theta$ versus force amplitude at point $\mathrm{A}$ for tests carried out at $3 \mathrm{~Hz}$.

quantity which is here involved is the trace of the Cauchy stress tensor $(\operatorname{tr}(\sigma))$, i.e. the sum of the principal stresses. Before presenting the results obtained, the principle of TSA is briefly recalled. First of all, assuming Fourier's law for heat conduction, the heat diffusion equation is written in case of isotropic material:

$\rho C \frac{\partial T}{\partial t}-k \Delta T=s_{h}+r_{e x t}$

where $T$ is the temperature, $r_{\text {ext }}$ the external heat source and $s_{h}$ the heat source produced or absorbed by the material itself. The material parameters are the density $\rho$, the thermal conductivity $k$ and the specific heat $C$ (assumed to remain constant during the deformation process). Temperature changes $\theta=T-T_{\text {ref }}$ are defined with respect to a reference temperature field $T_{r e f}$, defined when no heat source is produced by the specimen. If the external heat source $r_{\text {ext }}$ is assumed not to vary over the duration of the test (constant radiation), Eq. (1) becomes:

$\rho C \frac{\partial \theta}{\partial t}-k \Delta \theta=s_{h}$

For a thermoelastic behavior, the heat source $s_{h}$ produced by the material is composed of the thermoelastic (isentropic) coupling term and possibly mechanical (intrinsic) dissipation $d_{1}$. The latter is related to mechanical irreversibilities occurring in the material (to be distinguished to the thermal dissipation $d_{2}$ in the Clausius-Duhem inequality). It is defined as a non-negative quantity. For glass materials, which are assumed to behave as isotropic thermoelastic materials, the thermoelastic coupling term is written $-\alpha T_{0} \frac{\partial t r(\sigma)}{\partial t}$, where $\alpha$ is the coefficient of thermal expansion, $T_{0}$ the mean temperature of the specimen over the test (in

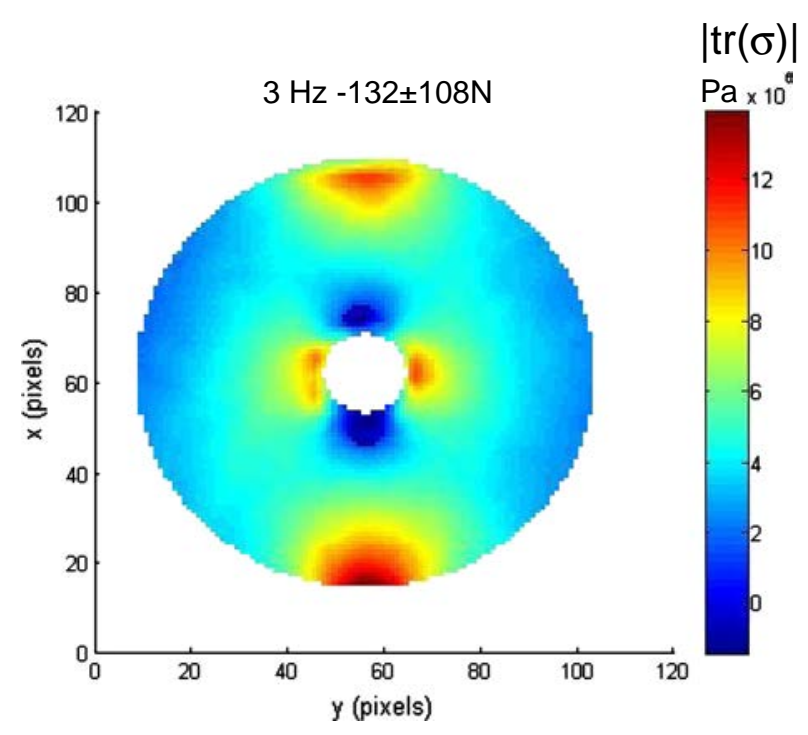

Fig. 6. Map of absolute value of $\operatorname{tr}(\sigma)$ at the specimen surface ( $3 \mathrm{~Hz}$ and $F=-132 \pm 108 \mathrm{~N}$ ).

Kelvin) and $\operatorname{tr}(\sigma)$ the trace (sum of principal stresses) of the Cauchy stress tensor $\sigma$. Thus we have:

$\rho C \frac{\partial \theta}{\partial t}-k \Delta \theta=-\alpha T_{0} \frac{\partial \operatorname{tr}(\sigma)}{\partial t}+d_{1}$

Eq. (3) shows that cyclic mechanical loading leads to a temperature variation composed of a global increase (due to mechanical dissipation $d_{1}$ ) and an oscillation at the same frequency as the load but in the opposite phase (due to thermoelastic coupling). If the loading frequency is sufficiently high, adiabatic conditions are achieved over one cycle, and consequently the conduction term can be neglected. As mechanical dissipation due to fatigue can be considered as negligible over one cycle, the range of temperature oscillation $\Delta \theta$ during one cycle is directly proportional to the range $\Delta \operatorname{tr}(\sigma)$ of the trace of the Cauchy stress tensor:

$\Delta \theta=-A \Delta \operatorname{tr}(\sigma)$

where $A$ is equal to $\frac{\alpha T_{0}}{\rho C}$. This gives rise to numerous applications in the field of thermoelastic stress analysis. The reader can refer to $[17,18]$ for further information. For the material considered in this study, parameter $A$ is equal to $4.6410^{-3} \mathrm{~K} / \mathrm{MPa}$ at $25^{\circ} \mathrm{C}$. In other words, such an approach provides three times the hydrostatic stress level. This quantity is

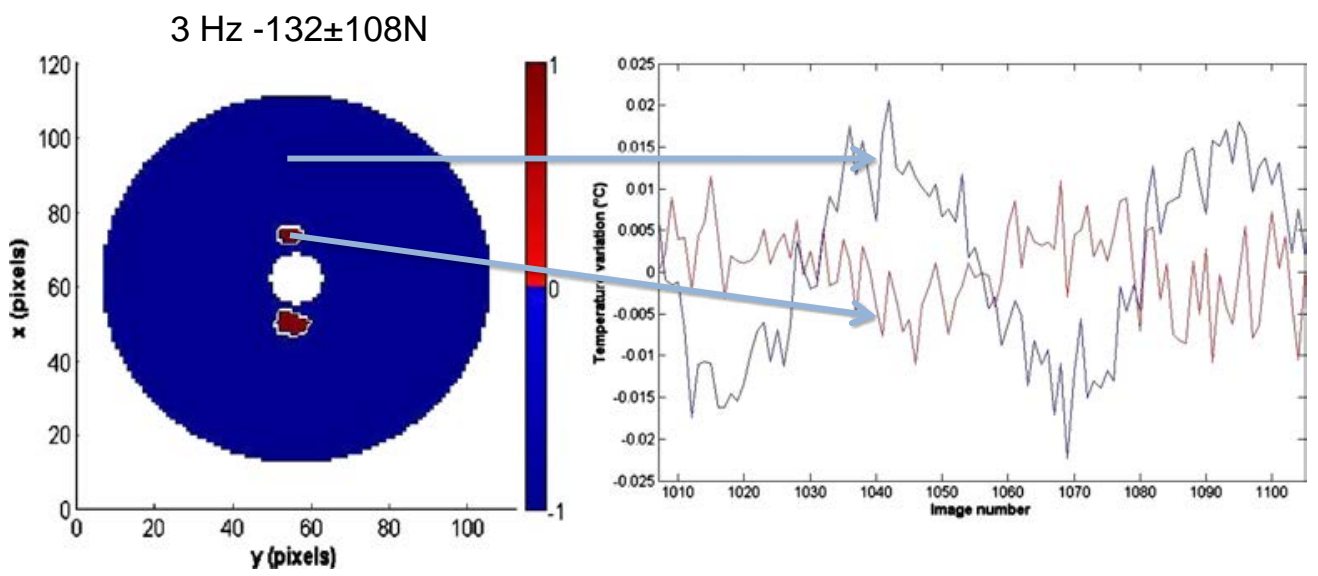

Fig. 5. Map of the sign of temperature change at $3 \mathrm{~Hz}$ and $F=-132 \pm 108 \mathrm{~N}$. Temperature change in the two different zones oscillates in the opposite phase. 
important if we consider that numerous glass materials are subject to densification [16]. As previously shown in Fig. 2, no significant difference is obtained in terms of temperature change range at a given force range between 1 and $3 \mathrm{~Hz}$. This indicates that the test at $1 \mathrm{~Hz}$ can be considered as adiabatic at the spatial scale of the temperature measurement. This can be validated by calculating the thermal flux due to conduction at the specimen surface. This calculation was carried out with the temperature change fields obtained at $3 \mathrm{~Hz}$, and led to a value for the diffusion term $-D \Delta \theta$ (where $D$ is the thermal diffusivity of the material) that is of the order of $10^{-10}{ }^{\circ} \mathrm{C} / \mathrm{s}$ at its maximum in the specimen during the cycle. This is negligible compared to the contribution of thermoelastic coupling, whose order of magnitude was equal to $10^{-1}{ }^{\circ} \mathrm{C} / \mathrm{s}$. In order to account for the local mechanical state, the temperature change range has to be signed. Fig. 5(a) presents the map of the sign of temperature change range. The abscissa axis is the number of images. As the acquisition frequency is equal to $147 \mathrm{~Hz}$, the unit of the axis can be converted in time by dividing the number of images by 147 . The map shows that the zones on both sides of the hole in the load direction varied in phase opposition to the rest of the surface, meaning that under global compression, these zones were under tension, and conversely. This is illustrated in Fig. 5(b). Obviously, the precise nature of the mechanical field cannot be defined from this quantity, in the sense that we measure here scalars while the stress is a second-order tensorial quantity. From the previous results and Eq. (4), Fig. 6 shows the map of the absolute value of $\operatorname{tr}(\sigma)$. This enabled us to locate the zones of highest hydrostatic pressure. In addition, it showed that the maximum hydrostatic pressure in absolute value was observed in the vicinity of the contact zones and reached $13.7 / 3=4.6 \mathrm{MPa}$.

\section{Conclusion and perspectives}

This study investigated the thermoelastic behavior of chalcogenide glasses of the AsSe system. For this purpose, an original experiment was developed to measure the thermal field at the surface of an AsSe glass specimen submitted to cyclic mechanical loading. The specimen geometry was chosen in such a way that a high stress gradient was induced during the deformation of the glass. The temperature field was measured by means of infrared thermography. The framework of thermal stress analysis (TSA) was then used to map the stress field at the surface of the specimen by processing the thermal field. The main result is that classical thermoelastic response is observed in chalcogenide glass without disturbances such as photo-irradiation. In other words, the thermal response during a cyclic mechanical test at sufficiently high frequency is proportional to the loading level applied to the specimen. This study demonstrates that TSA is an interesting tool for investigating the thermoelastic sensitivity of chalcogenide glasses. This is the first step before characterizing phenomena such as fatigue or cracking.

\section{References}

[1] O.U. Vonwiller, Notes on the elastic properties of selenium, Nature 104 (1919) 345-347.

[2] H. Hisakuni, K. Tanaka, Optical microfabrication of chalcogenide glasses, Science 270 (1995) 974-975

[3] H. Fritzsche, Photo-induced fluidity of chalcogenide glasses, Solid State Commun. 99 (1996) 153-155

[4] S.N. Yannopoulos, M.L. Trunov, Photoplastic effects in chalcogenide glasses: a review, Phys. Status Solidi B 246 (2009) 1773-1785.

[5] R. Golovchak, L. Calvez, E. Petracovschi, B. Bureau, D. Savytskii, H. Jain, Incorporation of Ga into the structure of Ge-Se glasses, Mater. Chem. Phys. 138 (2013) 909-916.

[6] B.L. Halfpap, S.M. Lindsay, Rigidity percolation in the germanium - arsenic - selenium alloy system, Phys. Rev. Lett. 57 (1986) 847-849.

[7] R. Boehmer, C.A. Angell, Correlations of the nonexponentiality and state dependence of mechanical relaxations with bond connectivity in germanium - arsenic-selenium supercooled liquids, Phys. Rev. B Condens. Matter 45 (1992) 10091-10094.

[8] R. Bohmer, C.A. Angell, Elastic and viscoelastic properties of amorphous selenium and identification of the phase transition between ring and chain structures, Phys. Rev. B Condens. Matter 48 (1993) 5857-5864.

[9] E. Lebourhis, P. Gadaud, J.-P. Guin, N. Tournerie, X.H. Zhang, J. Lucas, T. Rouxel, Temperature dependence of the mechanical behaviour of a GeAsSe glass, Scr. Mater. 45 (2001) 317.

[10] J.-P. Guin, T. Rouxel, J.-C. Sangleboeuf, I. Melscoet, J. Lucas, Hardness, toughness, and scratchability of germanium - selenium chalcogenide glasses. protect, J. Am. Ceram. Soc. 85 (2002) 1545

[11] J.C. Mauro, A.K. Varshneya, Modeling of rigidity percolation and incipient plasticity in germanium-selenium glasses, J. Am. Ceram. Soc. 90 (2007) 192-198.

[12] A.K. Varshneya, D.J. Mauro, B. Rangarajan, B.F. Bowden, Deformation and cracking in $\mathrm{Ge}-\mathrm{Sb}-\mathrm{Se}$ chalcogenide glasses during indentation, J. Am. Ceram. Soc. 90 (2007) 177-183.

[13] G. Delaizir, J-C. Sangleboeuf, C.E.A. King, Y. Gueguen, X.-H. Zhang, C. Boussard-Pledel, B. Bureau, P. Lucas, Influence of ageing conditions on the mechanical properties of Te-As - Se fibres, J. Phys. D. Appl. Phys. 22 (2009) (095405/095401-095406).

[14] G. Yang, B. Bureau, T. Rouxel, Y. Gueguen, O. Gulbiten, C. Roiland, E. Soignard, J.L Yarger, J. Troles, J.-C. Sangleboeuf, et al., Correlation between structure and physical properties of chalcogenide glasses in the $\mathrm{As}_{\mathrm{x}} \mathrm{Se}_{1}-\mathrm{x}$ system, Phys. Rev. B Condens. Matter 82 (2010) (195206/195201-195208).

[15] Y. Gueguen, T. Rouxel, P. Gadaud, C. Bernard, V. Keryvin, J.-C. Sangleboeuf, Hightemperature elasticity and viscosity of $\mathrm{Ge}_{\mathrm{x}} \mathrm{Se}_{1}-\mathrm{x}$ glasses in the transition range, Phys. Rev. B Condens. Matter 84 (2011) (064201/064201-064201/064210).

[16] Y. Gueguen, V. Keryvin Ellyn, A. King J.-C. Sangleboeuf, T. Rouxel, B. Bureau, Pierre Lucas, Photoinduced aging and viscosity evolution in Se-rich $\mathrm{Ge}-\mathrm{Se}$ glasses, J. Appl. Phys. 114 (2013) 074901.

[17] J.M. Dulieu-Barton, E.G. Little, J. Eaton-Evans, I.A. Brown, Thermoelastic analysis of high pressure angioplasty balloons, Strain 44 (2007) 102-118.

[18] N. Sathon, J.M. Dulieu-Barton, Evaluation of sub-surface stresses using thermoelastic stress analysis, Appl. Mech. Mater. 7/8 (2007) 153-158.

[19] J.-B. Le Cam, E. Robin, X. Balandraud, E. Toussaint, A new experimental route in thermomechanics of inorganic glasses using infrared thermography, J. Non-Cryst. Solids 366 (2013) 64-69 